Proceedings of the XXIII Conference on Applied Crystallography, Krynica Zdrój, Poland, September 20-24, 2015

\title{
Corrosion Resistance of Tin Coatings Deposited by Different Methods
}

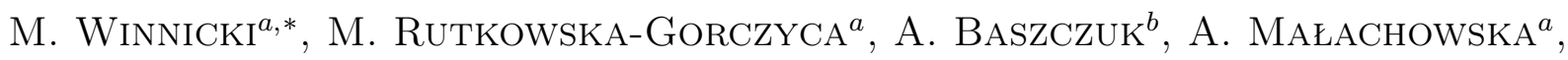 \\ T. PIWOWARCZYK ${ }^{a}$ AND A. AMBROZIAK ${ }^{a}$ \\ ${ }^{a}$ Department of Materials Science, Strength and Welding Technology, Wrocław University of Technology, \\ Wyb. Wyspiańskiego 27, PL-50370 Wrocław, Poland \\ ${ }^{b}$ Department of Mechanics, Materials Science and Engineering, Wrocław University of Technology, \\ Wyb. Wyspiańskiego 27, PL-50370 Wrocław, Poland
}

\begin{abstract}
This article describes the study of corrosion resistance of tin coatings deposited onto aluminum alloy substrates using the low pressure cold spraying and electroplating methods. The chemical corrosion resistance was examined using the Kesternich and cyclic salt spray tests inside $\mathrm{SO}_{2}$ and $\mathrm{NaCl}$ climate chambers, respectively. The selected tests allowed simulation of the conditions of the coatings during service. The results were satisfactory for low pressure cold spraying coatings. Coatings produced by electroplating exhibit substantial corrosive losses due to their method of application and low thickness. Evaluation of corrosion were carried out by analyzing changes in the microstructure. Additionally, the physicochemical tests were carried out using X-ray diffraction to verify corrosion changes on the coatings surface.
\end{abstract}

DOI: 10.12693/APhysPolA.130.1155

PACS/topics: 61.05.cp, 68.35.bd, 81.15.Pq, 81.15.Rs, 81.65.Kn

\section{Introduction}

Tin coatings are widely used in the electrotechnical engineering to protect aluminum against electrochemical corrosion. Such corrosion occurs at the moment of aluminum contact with a metal of higher electrochemical potential, such as e.g. copper [1-3]. There are three commonly used methods of applying tin coatings: (i) electroplating, (ii) hot-dip coating, and (iii) thermal spraying [3]. Coatings produced by electroplating have low thickness, reaching up to $50 \mu \mathrm{m}$, hence they are recommended for use in less aggressive environments [2, 3]. Thicker coatings, exceeding $100 \mu \mathrm{m}$, can be obtained by hot-dip coating and by thermal spraying. Due to the low cost of the process and the final properties of the obtained coatings, electroplating and thermal spraying are the most commonly used [3].

Thermal spraying includes such methods as, e.g. flame, arc, and cold spraying. Flame and arc sprayed coatings are characterized by high porosity and strong oxidation, which reduces their corrosion protection capacities [4]. The latest method, very attractive for the corrosion resistance applications, is the cold spray method. One of the variations of this method is low pressure cold spraying (LPCS). In this method, a compressed working gas (usually air or nitrogen) is heated to a temperature in the range of $200-650^{\circ} \mathrm{C}$ and accelerated to supersonic velocities when passing through de Laval convergent-divergent nozzle $[5,6]$. Powder particles are accelerated by supersonic gas jet at a temperature lower than the melting point of the material. As a result of the high kinetic

*corresponding author; e-mail: marcin.winnicki@pwr.edu.pl energy, the solid state particles undergo plastic deformation upon contact with the substrate and mechanical and metallurgical bonding occurs.

The electroplating process requires immersion of whole aluminium element in prepared solution, which is both expensive and harmful to the environment. The cold spraying process enables covering a necessary, even small area of the substrate. The aim of the examinations was to assess and compare the corrosion resistance of tin coatings deposited onto aluminum substrates using the electroplating and LPCS methods.

\section{Materials and methods}

All coatings were deposited on the AA1350 substrates $7 \times 25 \times 100 \mathrm{~mm}^{3}$ in size. Prior to electrolytic plating process, substrate was degreased in a $100 \mathrm{~g} / \mathrm{l} \mathrm{NaOH}$ at $60^{\circ} \mathrm{C}$ for $1 \mathrm{~min}$ and rinsed with deionized water. Subsequently, samples were dipped in a 50 vol. $\% \mathrm{HNO}_{3}$ at $23^{\circ} \mathrm{C}$ for 5 min to activate the surface and rinsed with deionized water. Furthermore, zinc immersion pre-treatment process has been used to remove the residual oxides and to produce a thin layer of zinc to prevent re-oxidation of the aluminium surface [7-10]. To form a zinc layer, the substrate was immersed in a zinc solution of $25 \mathrm{~g} / \mathrm{l}$ of $\mathrm{ZnO}$ and $170 \mathrm{~g} / \mathrm{l} \mathrm{NaOH}$ at $23^{\circ} \mathrm{C}$ for $30 \mathrm{~s}$. In order to increase the density and adhesion of the layer, the substrate was immersed again in the $\mathrm{HNO}_{3}$ to remove the zinc layer and then in the zinc solution at $23^{\circ} \mathrm{C}$ for $30 \mathrm{~s}$, and doubly rinsed. Immediately after zincate solution bath the tin electrolytic plating process was carried out under the condition of $2 \mathrm{~A} / \mathrm{dm}^{2}$ and $75-80^{\circ} \mathrm{C}$ in the solution of $80 \mathrm{~g} / \mathrm{l} \mathrm{Na} \mathrm{SnO}_{3}$ and $8 \mathrm{~g} / \mathrm{l} \mathrm{NaOH}$.

LPCS coatings were deposited using commercially pure spherical Sn powder with particles size of $45 \pm 10 \mu \mathrm{m}$. Before spraying the samples were degreased and sand- 
blasted with alumina. The coatings were sprayed using a low pressure DYMET 413 device (Table I). Prior to the corrosion testing the sprayed samples were machined to simulate working conditions.

LPCS parameters.

TABLE I

\begin{tabular}{l|l}
\hline \hline powder & $\mathrm{Sn}$ \\
gas preheating temperature & $20{ }^{\circ} \mathrm{C}$ \\
gas pressure & $0.5 \mathrm{MPa}$ \\
traverse speed & $10 \mathrm{~mm} / \mathrm{s}$ \\
powder feeding rate & $40 \mathrm{~g} / \mathrm{min}$ \\
spraying distance & $20 \mathrm{~mm}$
\end{tabular}

The test in a salt spray chamber with cyclic salt spraying was performed according to polish standard PN-EN ISO 16701-2010P [11] with one modification. In the examinations, after finishing of each stage (A or B) the samples were left for another 12 hours at $22^{\circ} \mathrm{C}$ and humidity of $55 \% \mathrm{RH}$. The Kesternich test was performed according to polish standard PN-EN ISO 6988-2000P [12]. In both tests ultimately 18 cycles were performed, with a total examination time of 432 hours.

Samples after corrosion tests were analyzed with the Nikon Eclipse MA 200 optical microscope. The crosssections were prepared by cutting the sample $15 \mathrm{~mm}$ from the bottom edge.

$\mathrm{X}$-ray diffraction measurements were carried out using Rigaku Ultima IV Diffractometer with $\mathrm{Cu} \mathrm{K} \alpha$ irradiation $(\lambda=1.5406 \AA)$ within the range from $20^{\circ}$ to $90^{\circ}$ in $0.02^{\circ}$ steps with an exposure time of $4 \mathrm{~s}$ per point.

\section{Results and discussion}

\subsection{Initial macrostructure}

The microstructure of coatings prior to the corrosion test is shown in Figure 1. The average thickness of the plated tin coatings was $55 \mu \mathrm{m}$ (Figure 1a). In the plated coating there is a visible thin layer $(\approx 2.5 \mu \mathrm{m})$ of zinc, which remains after pre-treatment process. The thickness of the tin coatings deposited with LPCS was in the range of 250-300 $\mu \mathrm{m}$ (Figure $1 \mathrm{~b}$ ).
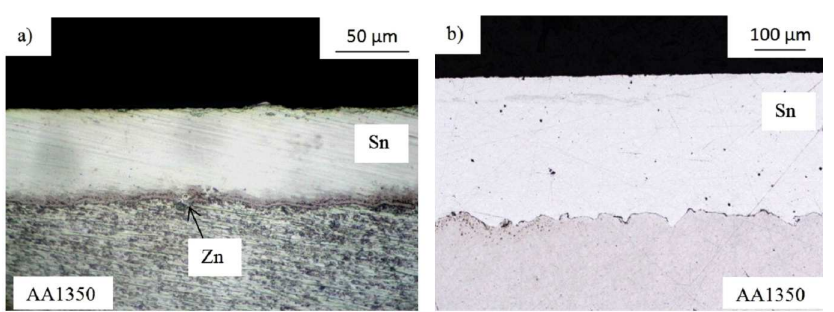

Fig. 1. Micrographs (light microscope) of coatings cross-section before corrosion tests: plated Sn coating (a), LPCS Sn coating (b).

\subsection{Macrostructure after corrosion tests}

The surfaces of tin coatings before and after corrosion tests are shown in Fig. 2. It was observed that none of the tested materials exhibited signs of corrosion after 1 cycle in $\mathrm{NaCl}$ atmosphere. However after 18 cycles complete dissolution of the coating and local corrosion centers were visible for sample with electroplated tin coating (Fig. 2b). For tin coating deposited using the Low Pressure Cold Spraying method no surface changes were observed (Fig. 2e).
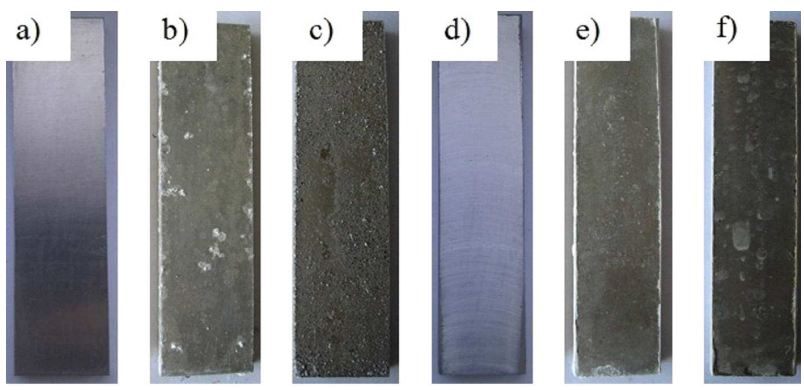

Fig. 2. Sn electroplated coating before tests (a), after 18 cycles in $\mathrm{NaCl}$ (b), after 18 cycles in $\mathrm{SO}_{2}$ (c), Sn LPCS coating after machining (d), after 18 cycles in

$\mathrm{NaCl}$ (e), after 18 cycles in $\mathrm{SO}_{2}$ (f).

No changes were visible on the surface of any tested samples after 1 cycle of the corrosion test in a climatic chamber with $\mathrm{SO}_{2}$. However after 4 cycles the macroscopic signs of corrosion were found on the surface of the sample with electroplated tin coating. After 18 cycles, about $80 \%$ of the surface exhibits aluminum corrosion (Fig. 2c). In contrast to electroplated tin coating for all coating deposited using the LPCS method no surface changes were observed (Fig. 2f).

\subsection{Microstructure of samples after corrosion tests}

Microstructure examination of all coatings by light microscopy lead to the conclusion that the plated tin coating exhibits much higher corrosion damages comparing to the LPCS coatings after both the salt spray and Kesternich tests. A dissolution of the plated coating in $\mathrm{NaCl}$ atmosphere was observed. The total thickness of the coating after the test was about $18 \mu \mathrm{m}$. Moreover also after the test in the $\mathrm{SO}_{2}$ environment significant dissolution and discontinuities in the plated tin coating were observed (Fig. 3a). The galvanic cells were created and as a result intensive corrosion of the substrate occurred. The thickness of the remaining after the test coating was only about $10 \mu \mathrm{m}$.
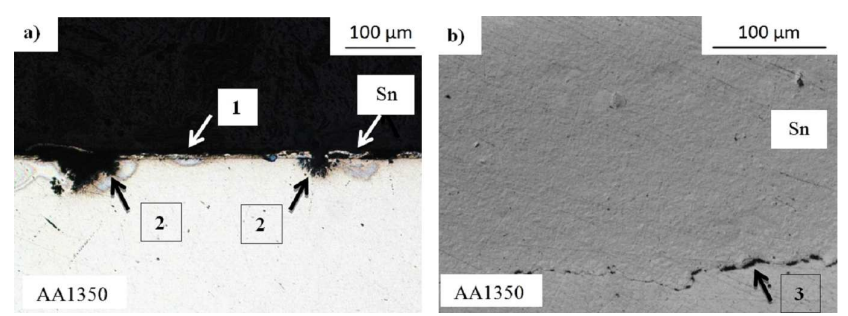

Fig. 3. Microstructure of electroplated (a) and LPCS (b) Sn coatings after tests in $\mathrm{SO}_{2} .1$ - dissolved coating, 2 - galvanic cells amplifying the substrate pitting corrosion, 3 - galvanic corrosion centres. 
The LPSC tin coating exhibited minor corrosion changes. The main corrosion areas occurred at the coating/substrate boundary and contained corrosion spots caused by galvanic corrosion (Fig. 3b). The spots were visible on the side of material with lower potential, i.e. aluminum alloy substrate. The tin coatings exhibit comparable changes after the salt spray and Kesternich tests. There was no thickness loss in LPCS coatings submitted to the Kesternich and the salt spray tests.

\subsection{Phase composition of coatings before and after corrosion tests}

In order to identify the phase composition of the coatings and the corrosion products characterize, XRD measurements were performed. The analysis of the diffraction patterns of all coatings before corrosion tests indicated typical reflections for tin with tetragonal structure $(\beta-\mathrm{Sn})$ at $2 \theta$ values of: $30.6^{\circ}, 32.1^{\circ}, 43.9^{\circ}, 45.1^{\circ}$, $55.4^{\circ}, 62.5^{\circ}, 63.8^{\circ}, 64.7^{\circ}, 72.5^{\circ}, 73.3^{\circ}, 79.6^{\circ}$. For electroplated tin coating additionally low intense diffraction peaks corresponding to AA1350 substrate were indicated. Microstructural changes after the corrosion tests in salt spray chamber were confirmed by XRD measurements (Fig. 4- left side). The main phase of all coatings was still tetragonal Sn with some low intensity peaks attributed to AA1350 substrate for electroplated tin coating. No additional diffraction peaks reflecting any corrosion products were seen. Microstructural observations showing after the test in $\mathrm{SO}_{2}$ chamber intensive corrosion for electroplated tin coating were confirmed by XRD measurements (Fig. 4 - right side). Several additional, small, broad peaks along with intense tin reflections appeared in the XRD pattern. These additional peaks did not fit exactly to any reaction product expected, but some correlation were found with $\mathrm{SnO}_{2}$ and $\mathrm{SnO}$ phases. One diffraction peak at $2 \theta=42.7^{\circ}$ was attributed to $\mathrm{Zn}$ from the intermediate zinc layer.

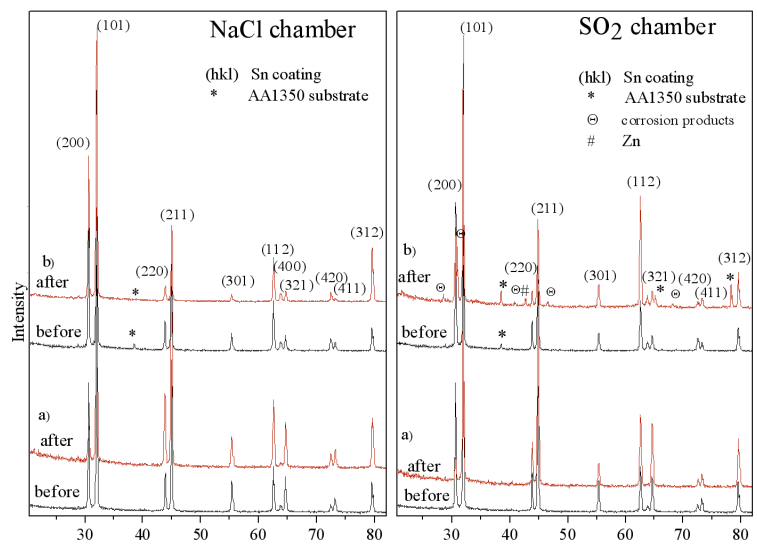

Fig. 4. XRD diffraction patterns of coatings before and after the salt spray and Kesternich corrosion tests: Sn coating deposited using the LPCS (a) and electroplated Sn coating (b).
In the diffraction pattern of tin coating deposited using the Low Pressure Cold Spraying after the test in $\mathrm{SO}_{2}$ chamber only intense peaks corresponding to tetragonal Sn were indicated. No additional diffraction peaks reflecting any corrosion products were detected.

\section{Conclusions}

The comparative tests of corrosion resistance of tin coatings obtained using electroplating and cold spray method clearly indicate higher corrosion resistance of the sprayed coatings. For plated tin coatings the significant changes in the total thickness and complete dissolution of some areas in coating layer were observed. The galvanic cells were created in these areas what resulted in the intensified progress of corrosion deep into the aluminum substrate material. On the contrary, the coatings deposited by LPCS method did not exhibit the loss of thickness, regardless of the applied corrosive environment.

\section{Acknowledgments}

The help of Prof. Lech Pawlowski of SPCTS in the correction of paper is acknowledged.

\section{References}

[1] Ch.G. Munger, L.D. Vincent, Corrosion Protection by Protective Coatings, National Association of Corrosion Engineers, Houston 1999.

[2] M.G. Fontana, Corrosion Engineering, Tata McGraw-Hill, New York 2005.

[3] C.J. Evans, Tin Handbook, Huthig Jehle Rehm, Heidelberg 1994.

[4] J.R. Davis, Handbook of Thermal Spray Technology, ASM International, Materials Park 2004.

[5] V.K. Champagne, The Cold Spray Materials Deposition Process - Fundamentals and Applications, Woodhead Publ., Cambridge 2007.

[6] R.G. Maev, V. Leshchynsky, Introduction to Low Pressure Gas Dynamic Spray, Wiley-VCH, Weinheim 2008.

[7] G.O. Mallory, J.B. Hajdu, Electroless Plating: Fundamentals and Applications, Cambridge University Press, Cambridge 1990.

[8] F.J. Monteiro, M.A. Barbosa, Surf. Coat. Technol. 35, 321 (1988).

[9] W. Deqing, S. Ziyuan, K. Tangshan, Surf. Coat. Technol. 191, 324 (2005).

[10] L. Wu, J. Zhao, Y. Xie, Z. Yang, Trans. Nonferrous. Met. Soc. China 20, 630 (2010).

[11] Standard: Corrosion of metals and alloys - Corrosion in artificial atmosphere - Accelerated corrosion test involving exposure under controlled conditions of humidity cycling and intermittent spraying of a salt solution, PN-EN ISO 16701, Polish Standards Association, Poland 2010.

[12] Standard: Metallic and other non-organic coatings Sulfur dioxide test with general condensation of moisture, PN-EN ISO 6988, Polish Standards Association, Poland 2000. 